\title{
Achieving gastroresistance without coating: formulation of capsule shells from enteric polymers
}

\author{
Joao A. C. Barbosa, Maha M. Al-Kauraishi, Alan M. Smith, Barbara R. Conway, Hamid A. \\ Merchant \\ Department of Pharmacy, School of Applied Sciences, University of Huddersfield, Queensgate, Huddersfield HD1 \\ 3DH, United Kingdom
}

\begin{abstract}
Capsules are a widely used oral dosage form due to their simplicity and ease of manufacture. They are equally popular for both pharmaceutical and nutraceutical products and since they do not need extensive formulation development; it is a dosage form of choice for new drugs undergoing animal or clinical trials. In addition to the standard hard-gelatin or cellulose-based vegetarian capsules, functional capsules such as those with built-in gastroresistance would be of great value. In this work, commonly used enteric polymers were investigated for the production of hard-capsules. The polymers used in this study included cellulose derivatives (HPMC AS-LF and HP-55) and acrylic/methacrylic acid derivatives (EUDRAGIT L100 and S100). A range of concentrations of polymers and plasticisers were tested to optimise the formulation for the production of capsule shells with desirable physicochemical and gastroresistance characteristics. Drug release from optimised capsules produced from HPMC AS-LF, HP-55, EUDRAGIT L100 and S100 was shown to be comparable to drug release from corresponding polymer-coated tablets in both compendial and physiological bicarbonate buffer. In summary, herein we report a simple method for producing enteric capsule shells which do not need an additional coating step which, if validated at large scale, can significantly reduce the cost of manufacturing of conventional enteric coated dosage forms and are also likely to improve the inter-tablet variability in post-gastric drug release inherent in coating variability in conventional coated dosage forms.
\end{abstract}

\section{Keywords:}

Capsules; enteric; Eudragit; HPMC; coating; Modified-release; delayed-release

Note: The published copy of this article is available at:

https://doi.org/10.1016/j.ejpb.2019.09.015

https://www.sciencedirect.com/science/article/pii/S093964111930606X 


\section{Introduction}

Capsules are one of the most common solid dosage forms employed for oral administration of active ingredients. With a global market valued at US $\$ 1.4 \mathrm{bn}$ in 2016 and an expected annual growth rate of $7.3 \%$, the empty capsule market is predicted to be worth roughly US $\$ 2.9 \mathrm{bn}$ in 2026 (FutureMarketInsights, 2016). Capsules are relatively simple to use compared with tablets which need more formulation development, take longer to produce and quality control. Capsules also present a more convenient delivery system for nutraceuticals (often powders) without the need to develop a complex formulation. Also, for drugs undergoing animal or clinical trials, capsules are often employed their simplicity and quick formulation turnaround for early stages of drug development.

Capsules can be manufactured in different sizes and materials, depending on their main purpose and content. Even though other materials are used, the large majority of capsules are still produced using gelatin (type A, type B and from fish bones) (Murachanian, 2010). Other materials were developed to meet the demand for non-animal based capsules which would address a growing need for halal and vegetarian/vegan markets (FutureMarketlnsights, 2016). The most common alternatives are HPMC, pullulan and starch based capsules (Capsugel®, 2019c; Qualicaps ${ }^{\circledR}, 2019$; Roxlor, 2019) which, although being a good substitute for gelatin, have limitations particularly when intended for enteric formulations as none of these materials have $\mathrm{pH}$-dependant solubility.

Nevertheless, when a gastroresistant formulation is required, the most conventional and common practice is to coat tablets with gastro-resistant polymers. Coating gelatin capsules is not a common industrial practice (Cerea et al., 2008) and a more common approach is to fill enteric coated granules or pellets into a conventional hard gelatin capsule. Hence, the allegedly simpler solid dosage form, becomes ever more complex. Therefore, if capsule shells can be prepared with built-in gastroresistance, they can be produced in bulk in a similar way to standard capsules. using a typical high-speed capsule filler This will have wide applications in controlling drug release and gastrointestinal targeting as it would also allow encapsulation of almost any drug or nutraceutical into empty shells for preclinical and clinical evaluation without extensive formulation development and can potentially reduce the research and development cost.

Previous attempts to produce enteric hard capsules have been reported in literature, however these rely on an additional coating step (AstraZeneca, 2017; Huyghebaert et al., 2004; Miller et al., 2015; Sharma and Sinha, 2018) or the incorporation of a gum which would provide protection to acid-sensitive ingredients by a delayed-release mechanism, such as DRCaps ${ }^{\mathrm{TM}}$ (Smith et al., 2010; Marzorati et al., 2015). These formulations do not exhibit a pH triggered release and instead rely on a time-delay in anticipation of timely emptying from stomach. Gastric emptying in reality is highly unpredictable (McConnell et al., 2008, Varum et al., 2010) rendering these products more vulnerable to inter- and intra-subject variability in gastric emptying (Davis et al., 1984; Ziessman et al., 2009), hence significantly affecting its gastroresistant functionality. Recently, Capsuge ${ }^{\circledR}$ and BioCaps ${ }^{\circledR}$ has developed cellulose based drug delivery technologies (enTRinsic ${ }^{\mathrm{TM}}$ and Bio-VXR respectively) which are claimed to provide full enteric protection without the need for functional coatings (Capsugel $\AA$, 2019b) (BioCaps $\AA, 2019$ ), however full composition is not disclosed and evidence of clinical efficacy is also very limited. Capsules based on acrylic polymers such as EUDRAGIT are not yet reported in the literature. Thus, in this work, we aimed to develop gastroresistant capsule shells using three of the most commonly used polymers in pharmaceutical industry for formulating gastroresistant dosage forms: hydroxypropyl methyl cellulose acetate-succinate (HPMC AS) and hydroxypropyl methyl cellulose phthalate (HPMC-P) and Methacrylic Acid - Methyl Methacrylate (Eudragit $\left.{ }^{\circledR}\right)$. 


\section{Materials and Methods}

\subsection{Materials}

The acrylic (Eudragit ${ }^{\circledR}$ L100 and S100) and cellulose based (HPMC AS-LF and HP-55) enteric polymers were provided in-kind as samples from Evonik Industries AG (Darmstadt, Germany) and Shin-Etsu (Chiyoda, Japan), respectively and their properties are summarised in Table 1. Sodium hydroxide, hydrochloric acid (37\%) and ethanol were purchased from Fisher Scientific (Loughborough, United Kingdom). Glycerol, lactose monohydrate, triethyl citrate and trisodium phosphate dodecahydrate $\geq 98 \%$ were purchased from Sigma-Aldrich (Dorset, United Kingdom). Ac-Di-Sol ${ }^{\circledR}$ SD-711 (croscarmellose sodium) and Kollidon ${ }^{\circledR} 30$ (povidone) were provided in kind by FMC Health and Nutrition (Ireland). Prednisolone was purchased from Severn Biotech, Ltd.

Table 1: Enteric polymers used in this study and their characteristics.

\begin{tabular}{|c|c|c|c|c|}
\hline Polymer & Brand name & Grade & $\begin{array}{l}\text { Dissolution } \\
\text { pH threshold }\end{array}$ & Manufacturer/ supplier \\
\hline \multirow{2}{*}{$\begin{array}{l}\text { Methacrylic acid } \\
\text { copolymer }\end{array}$} & \multirow{2}{*}{ EUDRAGIT $^{\circledR}$} & L100 & $\geq 6.0$ & \multirow{2}{*}{$\begin{array}{l}\text { Evonik Gmbh, } \\
\text { Darmstadt, Germany }\end{array}$} \\
\hline & & $\mathrm{S} 100$ & $\geq 7.0$ & \\
\hline $\begin{array}{l}\text { Hypromellose } \\
\text { acetate succinate }\end{array}$ & Aqoat $^{\circledR}$ & AS-LF & $\geq 5.5$ & \multirow{2}{*}{$\begin{array}{l}\text { Shin-Etsu Chemical Co., } \\
\text { Ltd., Japan }\end{array}$} \\
\hline $\begin{array}{l}\text { Hypromellose } \\
\text { phthalate }\end{array}$ & - & HP-55 & $\geq 5.5$ & \\
\hline
\end{tabular}

\subsection{Design and manufacture of capsule pin bars}

For the production of capsules, two sets of pins (capsule moulds) were fabricated with different dimensions: one for the body of the capsule and a second for the cap. Capsule pin bars were designed and manufactured in-house for a standardized capsule size "00", according to the reported dimensions for this size (Jones, 2004). The pins were produced using pharmaceutical grade stainless steel (316SS) rods, which were then machined to produce the pins of desired dimensions (Fig. 1A).

\subsection{Production of hard capsules}

To produce the capsule shells, the pins from Fig. 1A were immersed into the capsule formulation containing a gastroresistant polymer and other excipients. The pins were then withdrawn, inverted and the solution was allowed to dry to harden the shells, forming the cap and body of the capsule. The caps and bodies were then removed from the pins and cut to the desired length. At this stage, the capsule components were filled and assembled, forming a finished loaded capsule (Fig 1B).

\subsubsection{Capsule formulation}

Capsules were formulated using different concentrations of polymer (20-30\%) plasticised either with triethyl citrate (TEC) or glycerol at different concentrations (0-40\%). The tested formulations are summarised in Table 2. The polymer concentration was key in obtaining a capsule with appropriate thickness that could be easily removed from the pins. The polymer concentration also governs the viscosity of the prepared solution. An optimum viscosity is essential for the polymer to adhere to the pins during the drying process and produce a uniform capsule with the appropriate shape. The type and concentration of plasticiser impacts upon the capsule shell elasticity and prevents brittleness. 


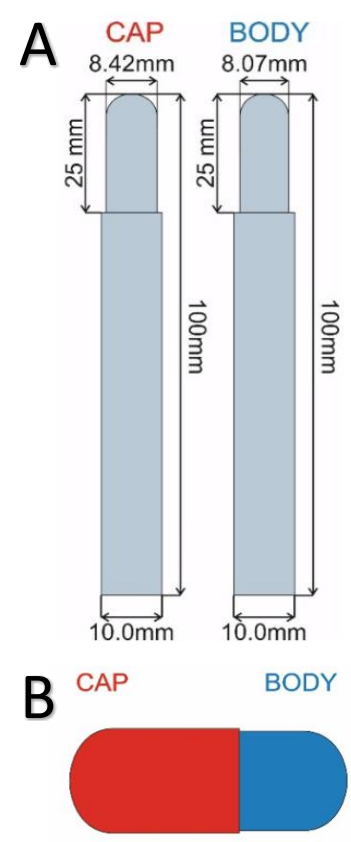

Fig. 1: Schematic representation of $[A]$ capsule forming pins and $[B]$ the capsule. The pins were immersed in polymeric solution, inverted and allowed to dry, forming the cap and body of the capsule.

Table 2: Composition of various formulations to produce gastroresistant capsule shells.

\begin{tabular}{|c|c|c|c|c|c|}
\hline Formulation ID & Polymer & $\%$ & Plasticiser & $\%$ & Solvent \\
\hline 1.1 & \multirow{4}{*}{ HP-55 } & 20.0 & Glycerol & 20.0 & \multirow{4}{*}{$\begin{array}{c}\text { Ethanol : Water } \\
\left(80: 20^{\mathrm{a}}\right)\end{array}$} \\
\hline 1.2 & & 20.0 & TEC & 20.0 & \\
\hline 1.3 & & 22.5 & Glycerol & 20.0 & \\
\hline 1.4 & & 22.5 & Glycerol & 30.0 & \\
\hline 2.1 & \multirow{5}{*}{ AS-LF } & 20.0 & Glycerol & 20.0 & \multirow{5}{*}{$\begin{array}{c}\text { Ethanol : Water } \\
\qquad\left(80: 20^{\mathrm{a}}\right)\end{array}$} \\
\hline 2.2 & & 20.0 & TEC & 20.0 & \\
\hline 2.3 & & 22.5 & Glycerol & 20.0 & \\
\hline 2.4 & & 25.0 & Glycerol & 20.0 & \\
\hline 2.5 & & 25.0 & Glycerol & 30.0 & \\
\hline 3.1 & \multirow{7}{*}{$\begin{array}{l}\text { EUD } \\
\text { L100 }\end{array}$} & 20.0 & Glycerol & 20.0 & \multirow{7}{*}{$\begin{array}{c}\text { Ethanol : Water } \\
\left(97: 3^{\mathrm{a}}\right)\end{array}$} \\
\hline 3.2 & & 20.0 & TEC & 20.0 & \\
\hline 3.2 & & 25.0 & TEC & 20.0 & \\
\hline 3.4 & & 25.0 & TEC & 30.0 & \\
\hline 3.5 & & 27.5 & TEC & 20.0 & \\
\hline 3.6 & & 27.5 & TEC & 30.0 & \\
\hline 3.7 & & 27.5 & TEC & 40.0 & \\
\hline 4.1 & \multirow{2}{*}{$\begin{array}{l}\text { EUD } \\
\text { S100 }\end{array}$} & 25.0 & TEC & 40.0 & \multirow{2}{*}{$\begin{array}{c}\text { Ethanol : Water } \\
\left(97: 3^{\mathrm{a}}\right)\end{array}$} \\
\hline 4.2 & & 27.5 & TEC & 40.0 & \\
\hline
\end{tabular}

HP-55 = Hypromellose phthalate-55; AS-LF = Hypromellose acetate succinate - LF; EUD L100 = Eudragit L100; EUD S100 = Eudragit S100; TEC = Triethyl citrate. 


\subsection{Tensile studies of produced capsules}

The mechanical properties of the polymeric materials used in the production of the capsules were studied using a TA.XT2 Texture analyser (Stable Micro Systems Ltd, Surrey, UK) equipped with tensile grips (tensile mode) and a cylinder probe (P/0.5"R; compressive mode). The films of each polymer were produced with the same formulation used for the capsules, casted on a flat surface and allowed to dry in the same conditions as the capsules would be. The thickness of the films was controlled by calculating the area of the surface where the film was casted, and constantly using a similar ratio of mass of polymer/area as it would be when using each formulation to produce the capsules. The films were then cut in dog-bone shaped pieces according to DIN EN ISO 527-2 for the determination of tensile properties, consisting of a rectangular area of $40 \times 8 \mathrm{~mm}$. For each sample an average thickness was acquired, and the stress area was calculated. The tests were performed at a speed of $0.5 \mathrm{~mm} / \mathrm{sec}$, at $20{ }^{\circ} \mathrm{C}$, with 10 replicates per sample. The slope of the linear range of the obtained stress vs. strain curves (tensile mode) is equal to the Young's modulus for the respective polymeric films.

\subsection{Prednisolone filled gastroresistant capsules}

All prepared capsules were filled with prednisolone granules prepared by wet granulation. Briefly, the formulation contained prednisolone $(5 \%)$, lactose monohydrate $(88 \%)$, Kollidon ${ }^{\circledR} 30(5 \%)$, Ac-Di-Sol ${ }^{\circledR}$ SD-711 (2\%). The ingredients were mixed using a Caleva Multi Lab (Caleva Process Solutions Ltd, England). The wet mass was then extruded and the extrudate was spheronized using the corresponding module from the Caleva Multi Lab followed by drying at $60{ }^{\circ} \mathrm{C}$. The granules were then filled manually into capsule shells to an equivalent of $10 \mathrm{mg}$ prednisolone per capsule.

\subsection{Drug release from prednisolone-filled gastroresistant capsules}

The drug release from prednisolone-filled capsules was tested using USP-II dissolution apparatus (PTDT70 Dissolution Apparatus, Pharma Test Apparatebau AG, Germany). Six capsules were tested for each successfully prepared formulation following the USP $<711>$ Dissolution monograph for delayedrelease dosage forms. Briefly, AS-LF, HP-55 and EUD L100 capsules were firstly tested in $0.1 \mathrm{M} \mathrm{HCl}$ $(\mathrm{pH} 1.2)$ for $120 \mathrm{~min}$ at $37^{\circ} \mathrm{C}$, followed by $\mathrm{pH} 6.8$ phosphate buffer $\left(0.05 \mathrm{M} \mathrm{Na}_{3} \mathrm{PO}_{4}\right.$, $\mathrm{pH}$ adjusted with $1 \mathrm{M} \mathrm{HCl} / 1 \mathrm{M} \mathrm{NaOH}$ ) or pH 6.8 mHanks buffer (Liu et al., 2011) (136.9 mM NaCl, $5.37 \mathrm{mM} \mathrm{KCl}, 0.812$ $\mathrm{mM} \mathrm{MgSO}_{4} \cdot 7 \mathrm{H}_{2} \mathrm{O}, 1.26 \mathrm{mM} \mathrm{CaCl}_{2}, 0.337 \mathrm{mM} \mathrm{Na}_{2} \mathrm{HPO}_{4} \cdot 2 \mathrm{H}_{2} \mathrm{O}, 0.441 \mathrm{mM} \mathrm{KH}_{2} \mathrm{PO}_{4}, 4.17 \mathrm{mM} \mathrm{NaHCO}_{3}$, $\mathrm{pH}$ adjusted to 6.8 using $\mathrm{CO}_{2}(\mathrm{~g})$ ). Capsules of EUD $\mathrm{S} 100$ were also produced and tested, however, since this polymer was designed to target the distal gut, the dissolution testing included two media changes to reflect the aboral changes in $\mathrm{pH}$ down the intestine. The capsules were firstly tested in $0.1 \mathrm{M}$ $\mathrm{HCl}$ ( $\mathrm{pH} 1.2$ for 2 hours) to represent gastric conditions followed by a change to $\mathrm{pH} 6.8$ (for 4 hours) to simulate the $\mathrm{pH}$ of the proximal small intestine. Finally, the $\mathrm{pH}$ was adjusted to 7.4 for the rest of the experiment simulating the distal small intestine. Like other capsules, the test was conducted in both phosphate and $m$ Hanks buffers, as described above in this section. For $m$ Hanks buffer, the pH change from $\mathrm{pH} 6.8$ to 7.4 was performed in situ by sparging helium and the $\mathrm{pH}$ was then maintained during the dissolution studies by sparging $\mathrm{CO}_{2}$, as described by Liu et al. (2011).

The release of prednisolone from HPMC AS-LF and EUDRAGIT capsules was quantified using an inline UV spectrophotometer (Unicam UV/Vis UV2-200 spectrophotometer) at a wavelength of $246 \mathrm{~nm}$. For the capsules containing HP-55, the release of the drug was quantified by HPLC-UV due to interference between the UV absorbance of the polymer and drug. The HPLC-UV system used was a Shimatzu LC-20AT with SIL-20A autosampler and an SPD-20AV UV detector. The samples were filtered through $0.2 \mu \mathrm{m}$ syringe filters (Sartorius ${ }^{\mathrm{TM}}$ Minisart ${ }^{\mathrm{TM}}$ High Flow) and injected into a reverse phase C8 $(5 \mu \mathrm{m}$ particle size, $4.6 \times 150 \mathrm{~mm})$ column (Waters, Massachusetts, USA). The column was heated to $40^{\circ} \mathrm{C}$ and the mobile phase consisted of a mixture of water:tetrahydrofuran:methanol $(68.8: 25: 6.2 \mathrm{v} / \mathrm{v})$ flowing at $1.5 \mathrm{~mL} / \mathrm{min}$. Prednisolone was detected at $254 \mathrm{~nm}$, at retention time of $2.7 \mathrm{~min}$ (Liu et al., 2011). 


\section{Results and discussion}

\subsection{Optimisation of capsule formulation}

Various polymeric formulations were tested to achieve optimum gastro-resistance from each enteric polymer. Table 3 summarises the final optimised formulation for each polymer that produced to a capsule with appropriate thickness, smoothness and gastroresistance. Lower concentrations of polymer and plasticiser yield thinner capsules, which either break during their removal from the pins or during handling. Lower concentrations of plasticiser also caused striations to appear along the capsule body during the drying process.

Table 3: Composition of optimised capsule formulations for each enteric polymer.

\begin{tabular}{lllll}
\hline & HP-55 & $\begin{array}{l}\text { HPMC } \\
\text { AS-LF }\end{array}$ & $\begin{array}{l}\text { EUDRAGIT® } \\
\text { L100 }\end{array}$ & $\begin{array}{l}\text { EUDRAGIT® } \\
\text { S100 }\end{array}$ \\
\hline Polymer weight & $22.5 \%^{\mathrm{a}}$ & $25 \%^{\mathrm{a}}$ & $27.5 \%^{\mathrm{a}}$ & $27.5 \%^{\mathrm{a}}$ \\
Glycerol & $30 \%^{\mathrm{b}}$ & $30 \%^{\mathrm{b}}$ & - & - \\
Triethyl citrate & - & - & $40 \%{ }^{\mathrm{b}}$ & $40 \%{ }^{\mathrm{b}}$ \\
Ethanol & $80 \%^{\mathrm{c}}$ & $80 \%^{\mathrm{c}}$ & $97 \%^{\mathrm{c}}$ & $97 \%^{\mathrm{c}}$ \\
Water & $20 \%^{\mathrm{c}}$ & $20 \%^{\mathrm{c}}$ & $3 \%$ & $3 \%$ \\
\hline a: based on total weight, b: based on polymer weight, c: based on solvent weight
\end{tabular}

All capsules were cut to appropriate length for "00" size (Jones, 2004) and their diameter was measured with a digital micrometer (Table 4). The produced capsules are shown in Fig 2. The dimensions of optimised capsule formulations were in accordance with the size and tolerances used by commercial suppliers of hard gelatin capsules (Capsuge $\left.{ }^{\circledR}, 2019 a\right)$.
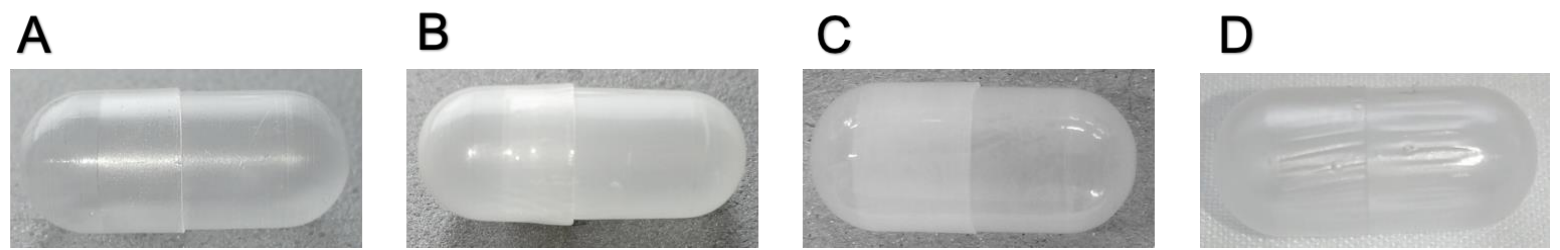

Fig. 2: Capsules obtained from optimised formulations for EUD L100 (A), AS-LF (B), HP-55 (C) and EUD S100 (D).

Table 4: Dimensions (mean $\pm S T D, n=6$ ) for the size "00" capsules produced from optimised formulations.

\begin{tabular}{|c|c|c|c|c|c|c|c|c|}
\hline & \multicolumn{2}{|c|}{ HP-55 } & \multicolumn{2}{|c|}{ HPMC AS-LF } & \multicolumn{2}{|c|}{ L100 } & \multicolumn{2}{|c|}{ S100 } \\
\hline & Body & Cap & Body & Cap & Body & Cap & Body & Cap \\
\hline $\begin{array}{l}\text { Outer Diameter } \\
(\mathrm{mm})\end{array}$ & $\begin{array}{l}8.51 \pm \\
0.04\end{array}$ & $\begin{array}{l}8.18 \pm \\
0.04\end{array}$ & $\begin{array}{l}8.52 \pm \\
0.03\end{array}$ & $\begin{array}{l}8.17 \\
\pm 0.03\end{array}$ & $\begin{array}{l}8.53 \pm \\
0.04\end{array}$ & $\begin{array}{l}8.16 \pm \\
0.02\end{array}$ & $\begin{array}{l}8.52 \pm \\
0.05\end{array}$ & $\begin{array}{l}8.17 \pm \\
0.02\end{array}$ \\
\hline Thickness (mm) & $\begin{array}{l}0.104 \pm \\
0.02\end{array}$ & $\begin{array}{l}0.097 \pm \\
0.01\end{array}$ & $\begin{array}{l}0.119 \pm \\
0.01\end{array}$ & $\begin{array}{l}0.104 \pm \\
0.02\end{array}$ & $\begin{array}{l}0.108 \pm \\
0.02\end{array}$ & $\begin{array}{l}0.114 \pm \\
0.02\end{array}$ & $\begin{array}{l}0.115 \pm \\
0.02\end{array}$ & $\begin{array}{l}0.109 \pm \\
0.01\end{array}$ \\
\hline
\end{tabular}

\subsection{Tensile strength}

From the stress vs strain plots obtained from the tensile tests on the polymeric films (Fig. 3), the elastic moduli were calculated and are summarised in Table 5. The measured Young's moduli of the polymers used in this work are comparable to reported values of gelatin used to formulate capsules (de Carvalho and Grosso, 2006; Park et al., 2007), exhibiting resistance to elastic deformation similar to that of standard gelatin capsules. It is worth noticing a lower yield point for the EUD S100 profile (Fig. 3), which is in line with brittleness of the $\mathrm{S} 100$ formulated capsules. Although the yield point was comparatively lower for these capsules ( $5 \mathrm{MPa})$, it may not adversely affect the mechanical stability of the capsule 
during packaging, storage or transportation. The Young's modulus for these films also suggests the resistance to elastic deformation was comparable to other polymers. Moreover, S100 capsules met the acid challenge test and the subsequent drug release in buffer was also satisfactory (refer s. 3.3 for further details).

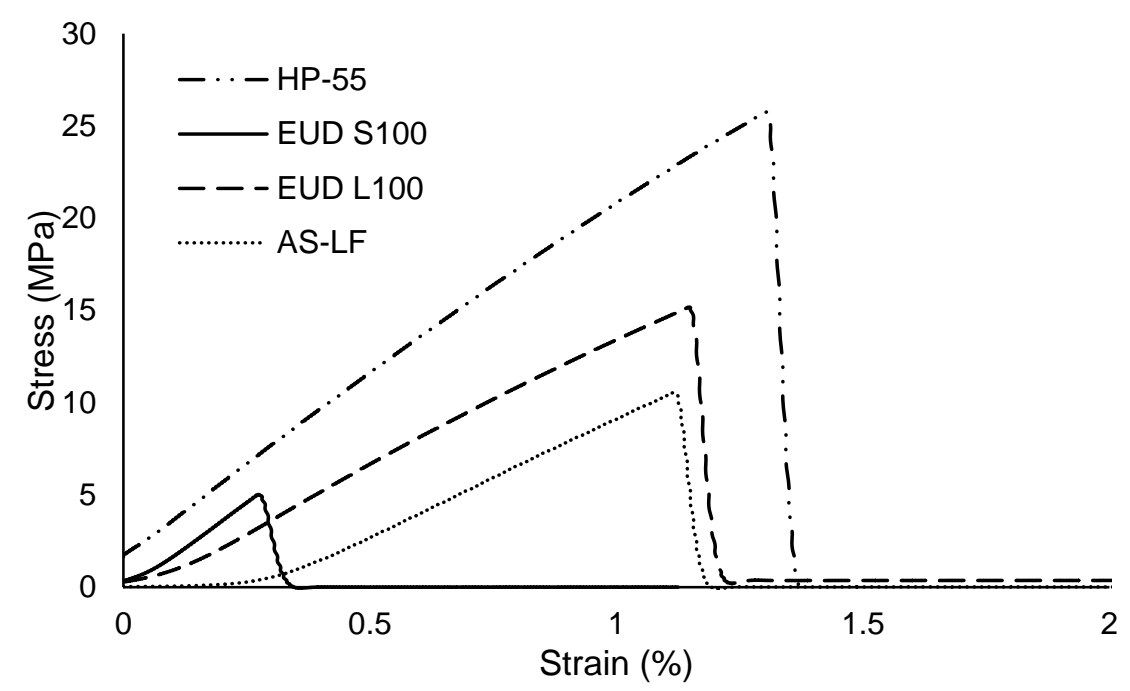

Fig. 3: Stress vs strain plots of HP-55, EUD L100, AS-LF and EUD S100 polymeric films. The slope of the linear region in profiles relates to the Young's modulus.

Table 5: Young's modulus of polymeric films used to formulate capsules shells. The values represents average \pm $\operatorname{STD}(n=9)$.

\begin{tabular}{ll}
\hline Polymer & Young's modulus (MPa) \\
\hline HPMC AS-LF & $15.61 \pm 2.10$ \\
HP-55 & $17.38 \pm 0.83$ \\
EUD L100 & $13.84 \pm 2.98$ \\
EUD S100 & $16.66 \pm 2.90$ \\
Gelatin & $19.5 \pm 1.6^{\mathrm{a}} ;$ \\
& $15.12 \pm 0.05^{\mathrm{b}}$ \\
\hline a: (Park et al., 2007); b: (de Carvalho and Grosso, 2006)
\end{tabular}

\subsection{Drug release from produced capsules}

Prednisolone release from optimised formulations (Table 3) for HPMC AS-LF, HP-55 and Eudragit L100 capsules is shown in Fig. 4A. There was no drug released during the first 2 hours in acid, confirming the acid resistance of the dosage forms as per pharmacopoeial requirements. All capsules ruptured rapidly exhibiting a drug release within $\sim 5 \mathrm{~min}$ on transfer to $\mathrm{pH} 6.850 \mathrm{mM}$ compendial phosphate buffer. The drug release from enteric capsules was therefore comparable to equivalent polymer-coated conventional gastroresistant tablets (Liu et al.,2011).

As expected, drug release in physiological bicarbonate buffer was delayed significantly and profiles between different polymers were not superimposable. Despite HPMC AS-LF and HP-55 being marketed for a dissolution $\mathrm{pH}$ threshold above $\mathrm{pH} 5.5$, their release profiles in bicarbonate buffer were discriminatory, despite being similar in phosphate buffer. Interestingly, prednisolone release from HPMC AS-LF capsules was similar in compendial phosphate and bicarbonate buffers, with a lag-time (time until at least $1 \%$ of drug is released) in the bicarbonate buffer of around 15 min compared to around 5 min in phosphate buffer. However, for HP-55 this lag time was much longer in bicarbonate buffer with no drug released until an hour in buffer. Eudragit L100 exhibited highest lag-time when tested 
in bicarbonate buffer, with the drug release delayed for 2 hours after transferring to the buffer phase. The much-delayed release of the drug from enteric capsules in physiological bicarbonate buffer was not surprising and also complies with previous reports of drug release behaviour from conventional enteric polymer-coated tablets in bicarbonate buffer (Liu et al. (2011).
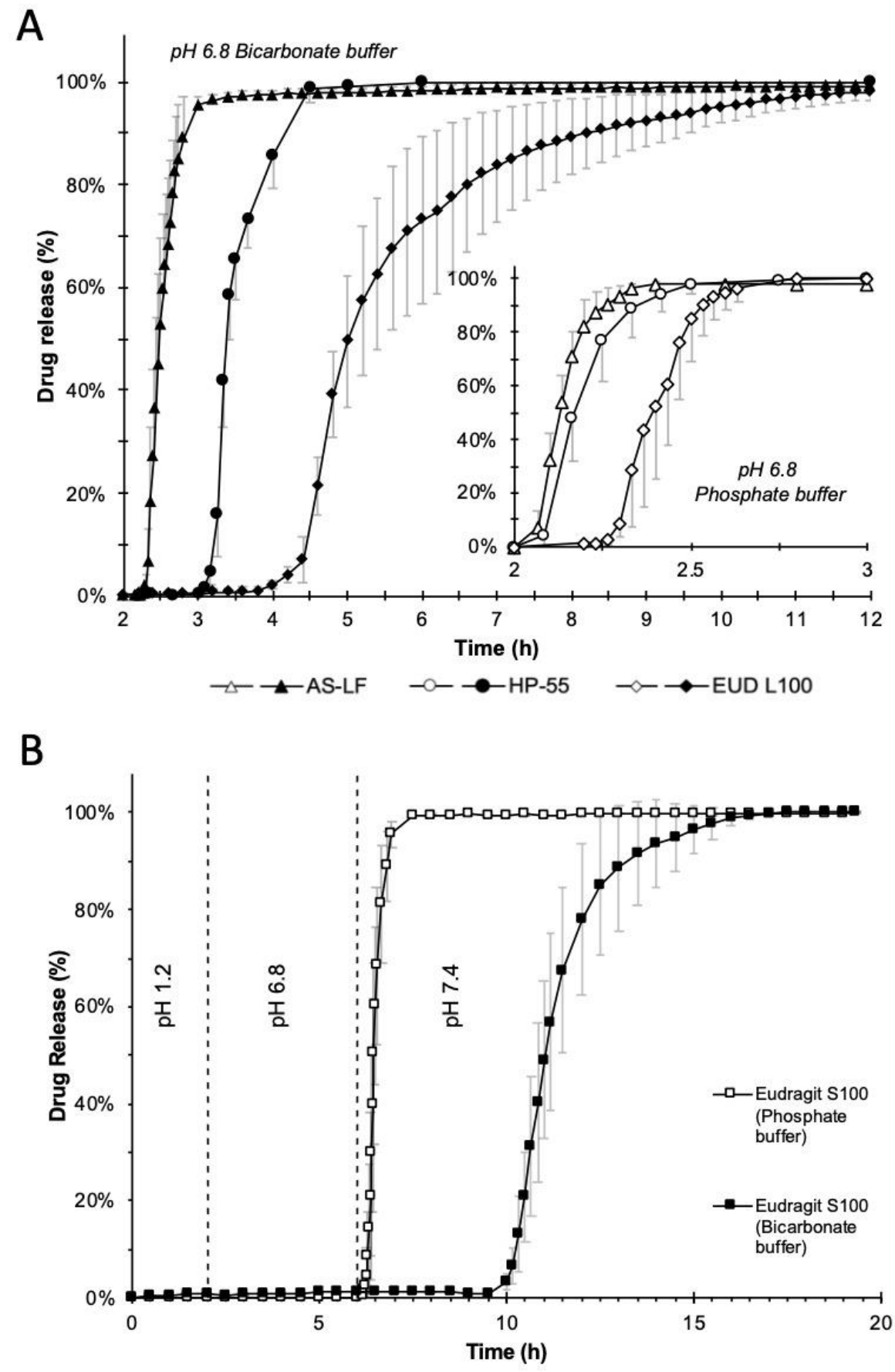

Fig. 4: Prednisolone release from enteric capsules $(n=6)$ in $50 \mathrm{mM}$ compendial phosphate buffer (empty symbols) and physiological bicarbonate buffer, mHanks (filled symbols). [A]: HP-55, EUD L100 and AS-LF capsules at pH 6.8 , after $2 \mathrm{~h}$-exposure to $0.1 \mathrm{M} \mathrm{HCl}$ (not shown); [B]: EUD $S 100$ capsules at $\mathrm{pH} 7.4$ following $2 \mathrm{~h}$ in $0.1 \mathrm{M} \mathrm{HCl}$ and 4 in $\mathrm{pH} 6.8$ buffer.

This suggests that the behaviour of the enteric polymers is similar when used as coatings on conventional tablets or to produce capsule shells. Although longer lag-times are observed for enteric capsules (Table 6) as compared with coated tablets in Liu et al. (2011), these can be attributed to the 
differences in the thickness of the capsule shells compared to the thickness of an enteric coating film applied to a tablet. The thickness of a typical coating on gastroresistant tablet varies about 50 to 75 microns with tablet edges usually thinly coated than the sides (Merchant, 2012), hence, coating around the edges mainly controls the lag-time in drug release. The enteric capsule shells on the other hand exhibited a uniform thickness $\sim 100$ microns (Table 4) which is twice more than the classic film coating. Nevertheless, the order in which the polymers start dissolving and the capsules start releasing the drug is the same as previously reported for coated tablets (Liu et al., 2011), exhibiting a rank order of time until drug release of HPMC AS-LF< HP-55< EUD L100. ASLF and HP-55 capsules are therefore suitable for gastroresistant applications to target the drug in proximal gastrointestinal tract, such as Deltacorti $^{\circledR}$, Nexium $^{\circledR}$, Voltarol $^{\circledR}$, Pariet $^{\circledR}$ etc.

Table 6: Lag time for the drug release (1\% release) from polymeric capsules and from conventional polymer-coated tablets at pH 6.8 (EUD L100, HP-55 and AS-LF) or pH 7.4 (EUD S100), pre-exposed to $0.1 \mathrm{M} \mathrm{HCl} \mathrm{pH} 1.2$ for $2 \mathrm{~h}$. Data from polymer-coated tablets from Liu et al. (2011) and lbekwe et al. (2006).

\begin{tabular}{lllllllll}
\hline & \multicolumn{3}{c}{ Lag times (min) in phosphate buffer } & \multicolumn{3}{c}{ Lag times (min) in bicarbonate buffer } \\
\hline & HP-55 & AS-LF & EUD L100 & EUD S100 & HP-55 & AS-LF & EUD L100 & EUD S100 \\
\hline Gastroresistant & 3.2 & 2.2 & 15.0 & 16.0 & 67.5 & 18.2 & 130.4 & 237.3 \\
Capsules & \pm 1.6 & \pm 0.4 & \pm 1.4 & \pm 4.0 & \pm 2.9 & \pm 2.7 & \pm 18.3 & \pm 8.1 \\
Coated Tablets & $5^{[1]}$ & $15^{[1]}$ & $11^{[1]}$ & $65^{[2]}$ & $35^{[1]}$ & $32^{[1]}$ & $77^{[1]}$ & $130^{[2]}$
\end{tabular}

HP-55 = Hypromellose phthalate-55; AS-LF = Hypromellose acetate succinate - LF; EUD L100 = Eudragit L100; EUD S100 = Eudragit S100. [1] Liu et al. (2011), [2] lbekwe et al. (2006)

The drug release profile from EUD S100 capsules is shown in Fig. 4B. These capsules were subjected to two media changes, the first to $\mathrm{pH} 6.8$ and the second to $\mathrm{pH} 7.4$. As expected, no drug release occurred during the acid phase (confirming gastroresistance) and in $\mathrm{pH} 6.8$ (both in phosphate and bicarbonate buffers) however the drug was released at $\mathrm{pH} 7.4$ within $15 \mathrm{~min}$ in phosphate buffer and a much-delayed release in bicarbonate buffer ( 4 hours). This slower release in bicarbonate buffer is not unexpected and longer lag times in this buffer were already reported by Goyanes et al. (2015). Therefore, L100/S100 based capsules are promising candidates to target pharmaceutical/nutraceutical agents to the distal gastrointestinal tract, such as Asaco ${ }^{\circledR}$, Octasa ${ }^{\circledR}$, Salofalk ${ }^{\circledR}$, pre/probiotics etc. The drug release from these capsules, however, can be improved by further optimising the capsule shell. For instance; using $\mathrm{pH}$ responsive polymer blends, such as: $\mathrm{S} 100 / \mathrm{L} 100$. A dual trigger system $(\mathrm{pH}$ and bacteria) comprising two independent but complementary release mechanisms can be embedded in capsule shells. This fail-safe system has recently shown promising results in the clinic in delivering high dose oral mesalazine to inflammatory bowel disease patients (D'Haens et al., 2017).

Intra- and inter-tablet coating variability in coated dosage forms is a significant factor responsible for the huge pharmacokinetics variability exhibited by these dosage forms for example Deltacortil (Merchant, 2012), which is further confounded by other variables such as gastric emptying time (McConnell et al., 2008). The capsules produced in this work do not need an additional coating step, and once translated to industrial production, the controllable and low variability of capsule wall thickness may reduce in-vivo variability associated with coating inconsistency in conventional products. Moreover, gastrointestinal targeting may be easily achieved by bespoke capsules shells produced at large scale where drug release can be tailored by the polymer blend and capsule wall thickness. 


\section{Conclusion}

We have successfully produced gastroresistant capsule shells that do not need additional coating to provide gastroresistance. A range of enteric polymers (HPMC derivatives and acrylate-based polymers) were used to produce enteric capsule shells to target various regions within the Gl tract: duodenum/jejunum - HPMC AS-LF and HP-55 (pH 5.5); ileocolonic - EUD L100 (pH 6.0); colon - EUD $\mathrm{S} 100(\mathrm{pH} 7.0)$. The produced capsules were very similar to classic immediate release hard gelatin capsules in appearance and resistance to elastic deformation. The technology, if warranted at industrial scale, can allow production of capsule shells in bulk, similar to conventional capsules, and will enable the industry to produce gastroresistant dosage forms without coating on a conventional capsule filling line. This will also be beneficial in early discovery and development in formulating gastroresistant dosage forms for preclinical and clinical trials.

\section{Acknowledgements}

Authors would like to acknowledge the Department of Pharmacy, School of Applied Sciences of the University of Huddersfield for the studentship to support this work, technical support from the School of Computing and Engineering at the University of Huddersfield for the fabrication of capsule pins, and $\mathrm{Dr}$ Vasileios Kontogiorgos for assistance with the texture analyser.

\section{References}

Astra Zeneca, 2017. Losec $^{\circledR}$ capsules - Summary of product characteristics. https://www.medicines.org.uk/emc/medicine/7275\#EXCIPIENTS Last accessed: 31/03/2019.

BioCaps $^{\circledR}, 2019$. Acid Resistant Vegetable Capsules Bio-VXR - BioCaps Enterprise. https://biocaps.net/portfolio/acid-resistant-vegetable-capsules/ Last accessed: 27/03/2019.

Capsuge ${ }^{\circledast}, 2019$ a. Capsuge ${ }^{\circledR}{ }^{\circledR}$ Vaps $^{\circledR}$ Capsule size information. https://www.capsugel.com/knowledge-center/vcaps-capsule-size-information Last accessed: 02/04/2019.

Capsuge $^{\circledR}$, 2019b. enTRinsic ${ }^{\mathrm{TM}}$ DDT | Capsugel. https://www.capsugel.com/biopharmaceuticaltechnologies/entrinsic-ddt Last accessed: 27/03/2019.

Capsuge ${ }^{\circledast}$, 2019c. Vcaps ${ }^{\circledR}$ Capsules. http://www.capsugel.com/consumer-healthnutrition/products/vcaps-capsules/ Last accessed: 31/03/2019.

Davis, S.S., Hardy, J.G., Taylor, M.J., Whalley, D.R., Wilson, C.G., 1984. The effect of food on the gastrointestinal transit of pellets and an osmotic device (Osmet). International Journal of Pharmaceutics 21, 331-340.

de Carvalho, R.A., Grosso, C.R.F., 2006. Properties of chemically modified gelatin films. Brazilian Journal of Chemical Engineering 23.

D'haens, G. R., Sandborn, W. J., Zou, G., Stitt, L. W., Rutgeerts, P. J., Gilgen, D., Jairath, V., Hindryckx, P., Shackelton, L. M., Vandervoort, M. K., Parker, C. E., Muller, C., Pai, R. K., Levchenko, O., Marakhouski, Y., Horynski, M., Mikhailova, E., Kharchenko, N., Pimanov, S. \& Feagan, B. G. 2017. Randomised non-inferiority trial: $1600 \mathrm{mg}$ versus $400 \mathrm{mg}$ tablets of mesalazine for the treatment of mild-to-moderate ulcerative colitis. Aliment Pharmacol Ther, 46, 292-302.

Future Market Insights, 2016. Empty Capsule Market: Increased demand for vegetarian empty capsules in developing markets to create significant revenue traction : Global Industry Analysis and Opportunity Assessment, 2016 - 2026. http://www.futuremarketinsights.com/reports/empty-capsules-market Last accessed: 31/03/2019. 
Goyanes, A., Hatton, G. B., Merchant, H. A., Basit, A. W., 2015. Gastrointestinal release behaviour of modifiedrelease drug products: Dynamic dissolution testing of mesalazine formulations. International Journal of Pharmaceutics 484 (1-2), 103-108.

Huyghebaert, N., Vermeire, A., Remon, J.P., 2004. Alternative method for enteric coating of HPMC capsules resulting in ready-to-use enteric-coated capsules. European journal of pharmaceutical sciences : official journal of the European Federation for Pharmaceutical Sciences 21, 617-623.

Ibekwe, V.C., Fadda, H.M., Parsons, G.E., Basit, A.W., 2006. A comparative in vitro assessment of the drug release performance of $\mathrm{pH}$-responsive polymers for ileo-colonic delivery. International Journal of Pharmaceutics 308, 52-60.

Jones, B.E., 2004. Manufacture and properties of two-piece hard capsules, in: Podczeck, F., Jones, B.E. (Eds.), Pharmaceutical Capsules, 2nd ed. Pharmaceutical Press.

Liu, F., Merchant, H.A., Kulkarni, R.P., Alkademi, M., Basit, A.W., 2011. Evolution of a physiological pH 6.8 bicarbonate buffer system: application to the dissolution testing of enteric coated products. European Journal of Pharmaceutics and Biopharmaceutics 78, 151-157.

Marzorati, M., Possemiers, S., Verhelst, A., Cadé, D., Madit, N., Van de Wiele, T., 2015. A novel hypromellose capsule, with acid resistance properties, permits the targeted delivery of acidsensitive products to the intestine. LWT - Food Science and Technology 60, 544-551.

Mcconnell, E. L., Fadda, H. M. \& Basit, A. W. 2008. Gut instincts: explorations in intestinal physiology and drug delivery. Int J Pharm, 364, 213-26.

Merchant, H. A. 2012. In-vitro, in-vivo and in-silico models in oral drug delivery and their relevance to human gastrointestinal physiology. Doctoral thesis, UCL School of Pharmacy, University College London, United Kingdom. ISNI: 000000042715 4798, Available onine at: http://ethos.bl.uk/OrderDetails.do?uin=uk.bl.ethos.550963

Miller, D.S., Parsons, A.M., Bresland, J., Herde, P., Pham, D.M., Tan, A., Hsu, H.-y., Prestidge, C.A., Kuchel, T., Begg, R., Aziz, S.M., Butler, R.N., 2015. A simple and inexpensive enteric-coated capsule for delivery of acid-labile macromolecules to the small intestine. Journal of Zhejiang University. Science. B 16, 586-592.

Murachanian, D., 2010. Two-Piece Hard Capsules for Pharmaceutical Formulations. Journal of GXP Compliance 10.

Park, H.-J., Yi, J.-B., Bae, H.-J., Kim, Y.-T., Cha, D.-S., 2007. Film-forming composition for hard capsules comprising fish gelatin and its preparation method. Patent number: WO2007/123350Al.

Qualicaps $^{\circledR}$, 2019. Pharmaceutical Applications. http://qualicaps.com/en/Capsules/pharma Last accessed: 30/03/2019.

Roxlor, 2019. Capsule Products. http://www.roxlor.com/products.php Last accessed: 31/03/2019.

Sharma, S., Sinha, V.R., 2018. Liquid Nanosize Emulsion-Filled Enteric-Coated Capsules for Colon Delivery of Immunosuppressant Peptide. AAPS PharmSciTech 19, 881-885.

Smith, A. M., Ingham, A., Grover, L. M., \& Perrie, Y. (2010). Polymer film formulations for the preparation of enteric pharmaceutical capsules. Journal of Pharmacy and Pharmacology, 62(2), 167-172. https://doi.org/10.1211/jpp.62.02.0003

Varum, F. J., Merchant, H. A. \& Basit, A. W. 2010. Oral modified-release formulations in motion: the relationship between gastrointestinal transit and drug absorption. Int J Pharm, 395, 26-36.

Ziessman, H.A., Chander, A., Clarke, J.O., Ramos, A., L.Wahl, R., 2009. The added diagnostic value of liquid gastric emptying compared with solid emptying alone. Journal of Nuclear Medicine 50, 726731. 